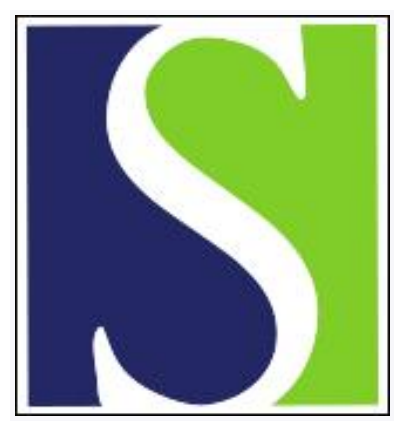

Scand J Work Environ Health 1995;21(6):435-439

https://doi.org/10.5271/sjweh.59

Issue date: Dec 1995

Social support, job strain and musculoskeletal pain among female health care personnel

by Ahlberg-Hultén GK, Theorell T, Sigala F

The following articles refer to this text: 2001;27(6):388-394;

2002;28(6):386-393; 2003;29(2):117-123; 2004;30(1):47-55

Key terms: female; health care personnel; job strain; low-back pain; musculoskeletal pain; neck pain; occupational stress; psychological stress; social support; woman

This article in PubMed: www.ncbi.nlm.nih.gov/pubmed/8824749 


\title{
Social support, job strain and musculoskeletal pain among female health care personnel
}

\author{
by Gunnel K Ahlberg-Hultén, BSc, ${ }^{1,2}$ Töres Theorell, MD, ${ }^{1,2}$ Filis Sigala, BSC ${ }^{1}$
}

\begin{abstract}
Ahlberg-Hultén GK, Theorell T, Sigala F. Social support, job strain and musculoskeletal pain among female health care personnel. Scand J Work Environ Health 1995;21:435-9.
\end{abstract}

\begin{abstract}
Objectives This study explored the relationship between psychosocial work environment and the musculoskeletal pain among health care personnel.

Materials and methods Ninety registered nurses and nurse's aides working in different hospitals in or just outside Stockholm and working in different kinds of care constituted the study group. Data were collected by means of questionnaires, including questions about symptoms (low-back pain, pain in the neck, and pain in the shoulders), the perception of social support from co-workers and superiors, conflicts, feelings of isolation, poor relations with superiors, psychological demands, authority over decisions, and skill utilization (job-strain factors).

Results An ordinal univariate logistic regression analysis showed that psychological demands, authority over decisions, skill utilization, and support at work had a statistically significant effect on symptoms from the lower back, while symptoms from the neck and shoulders were related to support at work only. When support at work and job strain were entered into a multivariate logistic regression model, a difference in the patterns of associations between low-back pain and symptoms from the neck and shoulders was found. Symptoms from the back were significantly related to job strain - the higher the strain, the more symptoms in the low back. Symptoms from the neck and shoulders on the other hand were more associated with social support at work the lower the support score the more severe the symptoms.

Conclusions Low-back pain seemed to be related to job strain, while symptoms from the neck and shoulders were to a greater extent related to relational and emotional factors.
\end{abstract}

Key terms low-back pain, neck pain, psychological stress, occupational stress, women.

Results from a previous study of personnel within cancer care (1) indicated that the emotional aspect of the work is very important. This aspect of health care work was also emphasized by Vachon (2). The emotional aspect consists of and could be described by means of a variety of concepts, for instance, the frequently used "emotional burnout." In the present work we have tried to emphasize a more positive aspect, using the concept "social support."

Considerable scientific interest has been focused on the importance of social support and its direct and indirect impact on health. The concept has been defined and measured in several different ways as described by, for instance, Shumaker \& Brownell (3) and Undén (4). The studies reported by Antonucci (5) and Payne \& Jones (6) mostly concern social support received in private settings from members of the family, relatives, and neighborhood. Buunk (7) has paid more attention to the effects of social support in organizations. He pointed out the different characteristics of social support received from family or friends on one hand and superiors or colleagues on the other. Caplan et al (8) reported that perceived lack of support from supervisors and others at work correlated more strongly with depression scores than did stressors such as role conflict, role ambiguity, and lack of participation.

Bongers and his colleagues $(9,10)$ have published reviews of the literature on psychosocial factors and musculoskeletal disease. The studies they refer to were based on different kinds of populations with a variety of designs. Social relations were found to be both negatively and positively associated with low-back pain in different studies. A longitudinal study by Bigos et al (11), in which adjustments were made for physical load and other potential confounders, showed a positive association between poor social relations at work with fellow workers

1 National Institute of Psychosocial Factors, Stockholm, Sweden.

2 Department of Occupational Medicin, Karolinska hospital, Stockholm, Sweden.

Reprint requests to: Gunnel Ahlberg-Hultén, Yrkesmedicinska enheten, Karolinska sjukhuset, 17176 Stockholm, Sweden. 
and episodes of back pain resulting in work absenteeism in the following three years. The results of studies on nonwork stressors have also been somewhat ambiguous. In some of them a relationship was reported between low-back pain and living alone, while in others no such relationship has been found. According to the few published studies analyzing social contacts outside the work environment, these may be of minor importance for back trouble. Karasek et al (12) also reported a much greater significance of work-related variables in the prediction of adverse health symptoms than variables from a nonwork situation. Bongers \& de Winter (9) found only 15 studies on the relationship between psychosocial factors at work and symptoms of the neck and shoulder region. Only two of these reported nonconflicting positive associations between poor social support and neck and shoulder pain $(13,14)$. In most of the cross-sectional studies a relationship between job demand variables and symptoms of the neck and shoulder region have been reported.

The objective of this study was to explore the relationship between social support at work and job strain on one hand and pain in the low back, shoulders and neck regions on the other among health care personnel.

\section{Subjects and methods}

This study was based on data from two investigations on the psychosocial work environment and health among health care personnel. The main and original aims of the two investigations were different, the first concerned the improvement of the psychosocial work environment through group discussions about work and the second concerned the special problems that may arise in treating drug addicts afflicted by infections. Except for the interviews in the different projects and the physiological data gathered in the first project, the methods and questionnaires in both projects were similar. In the present analysis, only female nurses and nurse's aides were included. There were significant differences between the men and women in the perception of received support. Furthermore, only nurses and nurse's aides are daily and directly exposed to the social atmosphere of hospital wards.

The remaining study sample consisted of personnel in an emergency ward $(\mathrm{N}=33)$, a pediatric outpatient

Table 1. Means, standard deviations and skewness coefficients for symptoms of low-back pain and pain in the neck and shoulders.

\begin{tabular}{lccc}
\hline Symptom $^{\mathrm{a}}$ & Mean & SD & Skewness \\
\hline Back pain & 1.71 & 0.96 & 1.0 \\
Pain in the neck & 1.72 & 1.03 & 1.09 \\
Pain in the shoulders & 1.39 & 0.83 & 2.17 \\
\hline
\end{tabular}

a For 90 subjects. clinic $(N=11)$, personnel from a specialized ward treating drug addicts afflicted by infections $(\mathrm{N}=13)$, an infectious disease ward treating patients $(\mathrm{N}=22)$ positive for human immunodeficiency virus (HIV), and personnel from a more traditional nonsomatic ward for drug addicts $(\mathrm{N}=11)$. The wards were located in different medium-sized hospitals in or just outside Stockholm, and the investigations were conducted between the autumn 1989 and spring 1992. The participation rate was $100 \%$ at the pediatric out-patient clinic, $89 \%$ at the emergency clinic, $86 \%$ at the regular infectious ward, $81 \%$ at the infectious ward for drug addicts, and $50 \%$ at the nonsomatic ward for drug addicts. The participation rate for the total group was $79 \%$. The age ranged from 19 to 59 years, averaging 34 years. There were 39 registered nurses and 51 nurse's aides, for a total of 90 participants.

\section{Musculoskeletal pain}

The three outcome variables back pain, pain in the neck, and pain in the shoulders were measured on a four-grade scale. The participants were questioned as to whether, during the last month, they had felt any of these symptoms - with alternatives from no to almost daily. The three variables were moderately positively skewed since a large proportion, $59 \%$ for pain in the back, $61 \%$ for pain in the neck, and $74 \%$ for pain in the shoulders, reported no symptoms (table 1). About $25 \%$ reported that they sometimes or almost daily felt pain in the back or neck, while only $12 \%$ felt pain in the shoulders with the same frequency.

\section{Nonworking factors}

The nonworking variables age, number of children, and "habital status" were considered to be potential confounding factors. Habital status was a dichotomized variable - women who were married or living with a man were treated as one group and singles with or without children as another group.

\section{Psychosocial factors at work}

The index measuring social support at work consisted of 16 positive and negative statements to which the respondents could agree or disagree on a four-grade scale from "yes, perfectly true" to "no, not at all true." A factor analysis divided 15 of these into five different dimensions (eigenvalues $>1$ ). The 16 th item, concerning difficulties with staff turnover, was omitted. The following five factors explained $71.6 \%$ of the variance in the total index: "positive factors" ("There is a calm and pleasant atmosphere at my workplace," "There is a good sense of fellowship," "My workmates support me," "If I have a 'bad day,' I'm met with acceptance," "I get on well with my superiors," and "I get on well with my workmates"), "feeling of isolation" ("I feel isolated from my workmates and somewhat outside of the fellowship," "There 
is nobody with whom I can talk about personal problems," and "There is nobody with whom I can talk about work-related problems"), "poor relations with superiors" ("My superior treats me condescendingly," "My superior is not capable of directing and distributing work," and "I am often in conflict with my superiors"), "conflicts" ("In accommodating some people, I have to disappoint others" and "There are often conflicts and fractions at my workplace") and stress ("There is a lot of stress in my work team") (table 2). All the groups except emergency ward personnel answered a question about what category or categories often showed them appreciation. The available alternatives were patients, superiors, colleagues, subordinates, and relatives of patients. The possible answers were "yes" or "no". Reporting patients as either the only category or" one of the categories showing appreciation was considered as receiving support from patients. A Swedish version of Karasek's demand-decision latitude questionnaire was used (15). The participants were asked to estimate the intensity of authority over decisions (2 items), psychological demands (5 items), and skill utilization ( 4 items). The quotient between psychological demands and the two "control" dimensions taken together formed a separate job strain variable.

\section{Physical load at work}

Physical strain may be an important confounding variable for symptoms of the musculoskeletal system. No such measure was available. A new variable was created on the basis of common-sense knowledge about physical demands in the different kinds of care. The pediatric outpatient clinic and the ward for drug addicts were rated as having light physical strain, while the emergency ward, the ward for drug addicts afflicted with infectious diseases, and the more regular ward for patients with infectious diseases were rated as having heavy physical strain.

\section{Statistics}

First a series of univariate ordinal logistic regressions were made with the three outcome variables as depend- ent variables. In an ordinal logistic regression an intercept parameter was estimated for every response level except the first, but there was only one slope parameter, the cumulative probability of being at or below each response level. In table 3 only the estimate of this slope parameter is given, which has a reversed direction from the estimates of the separate response levels. No estimates are given for variables on the nominal level. A second step consisted of multiple logistic regressions for ordinal responses with job strain and positive factors for the three different outcome variables. The rationale for choosing multiple logistic regressions with job strain and positive factors for the three different outcome variables was to explore whether the pattern observed in the univariate analysis remained significant when these independent variables were analyzed together.

\section{Results}

None of the nonworking factors (age, number of children or habital status) had any significant relationship to musculoskeletal pain in the univariate analysis. Nurse's aides did not differ significantly from nurses, and years of health care work had no importance for pain in the neck and shoulders. There was however a tendency towards a significant relationship between more years of health care work and more low-back pain.

Table 2. Means, standard deviations, range values, and skewness coefficients for the psychosocial scales.

\begin{tabular}{lrrrr}
\hline Psychosocial scale $^{a}$ & Mean & SD & Range & Skewness \\
\hline Positive factors & 19.5 & 3.3 & $6-24$ & -1.04 \\
Feeling of isolation & 4.0 & 1.6 & $3-11$ & 2.11 \\
Poor relations with superiors & 3.6 & 1.2 & $3-10$ & 2.48 \\
Conflicts & 3.5 & 1.2 & $2-6$ & 0.35 \\
Stress & 2.5 & 1.0 & $1-4$ & -0.22 \\
Psychological demands & 11.0 & 3.1 & $5-18$ & 0.25 \\
Skill utilization & 12.4 & 1.9 & $7-16$ & -0.32 \\
Authority over decisions & 5.1 & 1.7 & $2-8$ & -0.12 \\
Job strain & 0.66 & 0.2 & $0.23-1.12$ & 0.19 \\
\hline
\end{tabular}

a For 89 subjects.

Table 3. Univariate ordinal logistic regression estimates, chi-square values, and probability levels for low-back pain, neck pain, and pain in the shoulders.

\begin{tabular}{|c|c|c|c|c|c|c|c|c|c|}
\hline & \multicolumn{3}{|c|}{ Low-back pain } & \multicolumn{3}{|c|}{ Neck pain } & \multicolumn{3}{|c|}{ Shoulder pain } \\
\hline & $\begin{array}{l}\text { Esti- } \\
\text { mate }\end{array}$ & $\begin{array}{c}\text { Wald } \\
\chi^{2}\end{array}$ & $\begin{array}{c}\mathrm{P} . \\
\text { value }\end{array}$ & $\begin{array}{l}\text { Esti- } \\
\text { mate }\end{array}$ & $\begin{array}{c}\text { Wald } \\
\chi^{2}\end{array}$ & $\begin{array}{c}P_{-} \\
\text {value }\end{array}$ & $\begin{array}{l}\text { Esti- } \\
\text { mate }\end{array}$ & $\begin{array}{c}\text { Wald } \\
\chi^{2}\end{array}$ & $\begin{array}{c}\text { P. } \\
\text { value }\end{array}$ \\
\hline Psychological demands & -0.15 & 4.83 & 0.03 & 0.00 & 0.00 & 0.97 & 0.05 & 0.30 & 0.58 \\
\hline Authority over decisions & 0.24 & 3.65 & 0.05 & 0.05 & 0.14 & 0.71 & 0.08 & 0.29 & 0.59 \\
\hline Skill utilization & 0.21 & 3.71 & 0.05 & -0.03 & 0.12 & 0.73 & 0.09 & 0.48 & 0.49 \\
\hline Job strain & -2.93 & 7.38 & 0.01 & -0.43 & 0.18 & 0.67 & -0.44 & 0.12 & 0.73 \\
\hline Support from patients & $\cdot$ & 8.24 & 0.22 & $\cdot$ & 1.11 & 0.98 & . & 7.17 & 0.31 \\
\hline Poor relations with superiors & 0.14 & 0.55 & 0.46 & -0.14 & 0.70 & 0.40 & 0.07 & 0.10 & 0.75 \\
\hline Feeling of isolation & -0.09 & 0.60 & 0.44 & 0.01 & 0.01 & 0.92 & -0.04 & 0.07 & 0.79 \\
\hline Conflicts & -0.32 & 3.26 & 0.07 & 0.11 & 0.40 & 0.52 & 0.17 & 0.59 & 0.44 \\
\hline Stress & -0.12 & 0.30 & 0.58 & 0.08 & 0.13 & 0.72 & 0.02 & 0.01 & 0.92 \\
\hline Positive factors & 0.13 & 3.95 & 0.05 & 0.12 & 3.51 & 0.06 & 0.15 & 4.33 & 0.04 \\
\hline
\end{tabular}


Table 4. Multiple ordinal logistic regression estimates, chi-square values, and probability levels for job strain and positive factors on lowback pain, neck pain and pain in the shoulders.

\begin{tabular}{|c|c|c|c|c|c|c|c|c|c|}
\hline & \multicolumn{3}{|c|}{ Low-back pain } & \multicolumn{3}{|c|}{ Neck pain } & \multicolumn{3}{|c|}{ Shoulder pain } \\
\hline & $\begin{array}{l}\text { Esti- } \\
\text { mate }\end{array}$ & $\begin{array}{c}\text { Wald } \\
\chi^{2}\end{array}$ & $\begin{array}{c}\mathrm{P}- \\
\text { value }\end{array}$ & $\begin{array}{l}\text { Esti- } \\
\text { mate }\end{array}$ & $\begin{array}{c}\text { Wald } \\
\chi^{2}\end{array}$ & $\begin{array}{c}\mathrm{P}- \\
\text { value }\end{array}$ & $\begin{array}{l}\text { Esti- } \\
\text { mate }\end{array}$ & $\begin{array}{c}\text { Wald } \\
\chi^{2}\end{array}$ & $\begin{array}{c}\mathrm{P}- \\
\text { value }\end{array}$ \\
\hline Job strain & -2.59 & 4.61 & 0.03 & 0.59 & 0.25 & 0.62 & 0.94 & 0.41 & 0.52 \\
\hline Positive factors & 0.05 & 0.49 & 0.48 & 0.13 & 3.38 & 0.07 & 0.18 & 4.41 & 0.04 \\
\hline
\end{tabular}

A high frequency of low-back pain was significantly related at the 0.05 level to high psychological demands, low skill utilization, low authority over decisions, and a low positive factors score and at the 0.01 level to a high job-strain ratio (table 3 ). Frequent pain in the shoulders was significantly related to a low positive factors score, and frequent pain in the neck was almost significantly related to a low positive factors score. When job strain and positive factors were entered into a multiple ordinal logistic regression with the three outcome variables, there was no longer a significant relationship between positive factors and low-back pain (table 4). The most important factor for low-back pain was job strain, while for pain in the neck and shoulders, positive factors were the most important.

\section{Discussion}

The main finding in the present study was the difference between low-back pain on one hand and symptoms from the upper back or neck and shoulders on the other. Symptoms from the lower back were related to the perception of demands, the sense of control, and even more strongly to the combination of high demands and lack of control. Symptoms from the upper back region seemed to be more related to emotional and relational factors. The results support the idea that different factors affect symptoms of the back and symptoms of the neck and shoulders.

None of the variables were perfectly normally distributed; the skewness was in most cases moderate. With this condition and the framing of our questions in mind, ordinal logistic regression was considered to be the best available kind of analysis. The dependent variables were not dichotomized since such an operation would violate the information contained in the data, even if ordinal regressions may be somewhat more difficult to interpret. Both Spearman rank and Pearson's product-moment correlations were in accordance with the results from the ordinal logistic regressions. In order to facilitate interpretation, the estimates from the univariate analysis were translated into odds ratios and $95 \%$ confidence intervals (95\% CI) were computed for four different examples. The odds ratio for having any symptoms of back pain for high strain (upper quartile) versus low strain (lower quar- tile) was $1.73(95 \%$ CI $1.26-2.11)$, while the odds ratio for having symptoms from the low back sometimes or daily during the last month was 2.00 (95\% CI 1.442.25 ). Furthermore the odds ratio for having any symptoms of neck pain when reporting low support (lower quartile of positive factors) versus high support (upper quartile of positive factors) was 1.35 (95\% CI 1.06 1.5), and for having symptoms from the neck sometimes or daily it was $1.50(95 \%$ CI $1.13-1.5)$.

The studied group represents a broad range of different kinds of care and professional categories in hospital health care. Although not all specialties were represented, the group consisted of personnel from both an outpatient setting and regular wards and also from both somatic and psychiatric care. The participation rates were acceptable. The fact that both psychosocial data and reported symptoms were derived from questionnaires can be seen as a weakness, and it can be argued that the results were influenced by a "self-reporting artifact." There is, however, no a priori reason to believe that the different "patterns" of associations between low-back pain and pain in the neck and shoulders should be the result of, for instance, social desirability.

The scales of the support and nonsupport factors were constructed from a factor analysis with data from health care personnel, and it showed considerable consistency with respect to conceptual content. The Cronbach alpha for the different components of the job strain variables was lower for health care personnel than for other professional groups (16); therefore the concept of "psychological demands" and "control" may have a different meaning for this professional group. Future studies should include more specially adapted questions and scales.

The differences in the perception of social support between men and women was one of the reasons for omitting men from the analysis. The fact that the men perceived both superiors and workmates as less supportive than the women did suggests that men as a minority in a traditionally female "culture" may have difficulties in affiliation. If so, the phenomenon deserves further study. On the other hand, Antonucci (5) refers to several studies and points out that women in general have more extensive and more varied networks, while men are more dependent on their spouse. House (17) refers to a longitudinal study by Berkman \& Syme (18) of the signifi- 
cance of different kinds of social ties for the risk of dying within a period of nine years. Marriage had the strongest protective effect for men, while contacts with friends were the most protective for women. An earlier study by our group, with the same questions as in this study (19), showed that, among men and women in the same professions, women perceived more social support at work.

A qualitative analysis of interviews with newly employed personnel in long-time care (20) showed that young Swedish women were the ones who more easily than others identified themselves with their new professional caring role.

A previous study by our group also investigated the relationship between psychosocial job conditions and symptoms from the musculoskeletal system (16). The results in this report were based on a group of 147 men and 60 women in six different occupations. Unfortunately symptoms from the lower and upper back were grouped together in the analysis, but it may be interesting to note that conflicts at work, lack of possibility to talk, and high demands were positively correlated with "worry." Positive factors were negatively correlated with worry and anger. Symptoms from the back, neck, and shoulders together were positively related to a lack of possibility to talk and high demands but not to positive factors.

Viikari-Juntura et al (21) conducted a life-long prospective study on the role of psychosocial factors in neck-shoulder and low-back pain and found that, in adulthood among Finnish men and women, a poor sense of coherence was consistently associated with neck-shoulder pain, whereas low fundamental education predicted low-back symptoms. For women both poor social confidence and a weak sense of coherence predicted mild neck symptoms.

\section{References}

1. Ahlberg-Hultén G. Den psykosociala arbetsmiljön på Radiumhemmet i samband med ökad anhörigmedverkan [The psychosocial work environment in the Department of Oncology in connection with increased participation of relatives in the care of cancer patients]. Stockholm: Statens institut för Psykosocial Miljömedicin och institutionen för klinisk stressforskning vid Karolinska institutet, 1987. Stressforskningsrapport, no 194.

2. Vachon MLS. Occupational stress in the care of the critically ill, the dying, and the bereaved. New York (NY): Hemisphere Publishing Corporation, 1987.

3. Shumaker SAK, Brownell A. Towards a theory of social support: closing conceptual gaps. J Soc Issues 1984;40(4):1136.

4. Undén A-L, Social support and health: methodology, relationship to work and to ischaemic heart disease, kongliga Stockholm: Carolinska Medico Chirurgiska Institutet, 1991.
5. Antonucci TC. Social support: theoretical advances, recent findings and pressing issues. Boston (MA): The University of Michigan Survey Research Center, 1985.

6. Payne RL, Jones JG. Measurement and methodological issues in social support. In: Kasl SV, Cooper CL, editors. Stress and health: issues in research methodology. Chichester (United Kingdom): John Wiley \& Sons Ltd, 1987:167-205.

7. Buunk BP. Affiliation and helping interactions within organizations: a critical analysis of the role of social support with regard to occupational stress. In: Stroebe W, Hewstone M, editors. European review of social psychology, volume 1. Chichester: John Wiley \& Sons, 1990:293-322.

8. Caplan RD, Cobb S, French JRP, van Harrison R, Pinneau SR. Job demands and worker health, main effects and occupational differences. Washington (DC): US Department of Health, Education and Welfare, National Institute for Occupational Safety and Health, 1975.

9. Bongers PM, de Winter CR. Psychosocial factors and musculoskeletal disease: a review of the literature. Leiden (The Netherlands): Nederlands Instituut voor Praeventieve Gezondheidszorg TNO, 1992. TNO-rapport.

10. Bongers PM, de Winter CR, Kompier MAJ, Hildebrandt VH. Psychosocial factors at work and musculoskeletal disease [review]. Scand J Work Environ Health 1993;19:297-312.

11. Bigos SJ, Spengler DM, Martin NA, Zen J, Fisher L, Nochemson $A$, et al. Back injuries in industry: a retrospective study, III: employee-related factors. Spine 11 1986;11:252-6.

12. Karasek R, Gardell B, Lindell J. Work and non-work correlates of illness and behaviour in male and female white collar workers. J Occup Behav 1987;8:187-207.

13. Linton SI, Kamwendo K. Risk factors in the psychosocial work environment for neck and shoulder pain in secretaries. $J$ Occup Med 1989;31:609-13.

14. Linton SJ. Risk factors for neck and back pain in a working population in Sweden. Work Stress 1990;4:41-9.

15. Karasek RA. Job demands, job decision latitude and mental strain: implications for job redesign. Adm Sci Q 1979;24: 284-307.

16. Theorell T, Harms-Ringdal K, Ahlberg-Hultén G, Westin B. Psychosocial job factors and symptoms from the locomotor system: a multicausal analysis. Scand J Rehabil Med 1991;23: 165-73.

17. House JS. Work stress and social support. Reading (MA): Addison-Wesley Publishing Co, 1981.

18. Berkman LF, Syme SL. Social networks, host resistance and mortality: a nine year follow-up study of Alameda County residents. Am J Epidemiol 1979;109:186-204.

19. Theorell T, Ahlberg-Hultén G, Berggren T, Perski A, Sigala F, Svensson J, et al. Arbetsmiljö, levnadsvanor och risk för hjärt- och kärlsjukdom [Work environment, personal habits and heart disease risk]. Stockholm: Satens Institut för Psykosocial Miljömedicin, 1987. Stressforskningsrapporter, no 195.

20. Theorell T, Ahlberg-Hultén G, Jodko M, Sigala F, Söderholm M. Att förbättra arbetsmiljön i vård [Improvement of work environment within health care]. Stockholm: Statens Institut för Psykosocial Miljömedicin och Yrkesmedicinska kliniken, Karolinska sjukhuset, 1992. Stressforskningsrapporter, no 233.

21. Viikari-Juntura E, Vuori J, Silverstein BA, Kalimo R, Kuosma E, Videman TA. Life-long prospective study on the role of psychosocial factors in neck-shoulder and low-back pain. Spine 1991;16(9):1056-61.

Received for publication: 15 September 1994 